\title{
Labour Market Forecasting of the Russian Federation
}

\author{
Angelina Skobleva*, Irina Eremina, Denis Lysanov
}

\author{
Kazan Federal University, Kazan, Russian Federation \\ ${ }^{*}$ Corresponding author. Email: skobleva.lina@mail.ru
}

\begin{abstract}
The labour market is an important indicator of the living standards of the population and the development of the country's economy. Employment and unemployment indicators are among the key macroeconomic indicators on the basis of which they assess current trends and prospects for economic growth, investment attractiveness of countries and regions, risks and opportunities for business development. The formation and regulation of the labor market is one of the key and acute problems of the market economy. Maintaining the fullest employment is an important objective of the economic and social policies of any State. The aim of the study is to construct a forecast model of employment and unemployment using basic statistical analysis and forecasting methods. The analysis was carried out using the STATISTICA software package. The findings reflected developments in the coming period. As a result of the work, forecast models of employment and unemployment of the population of the Russian Federation were built.
\end{abstract}

Keywords: Labour market, Statistical analysis, Forecasting, Employment, Unemployment.

\section{INTRODUCTION}

The labour market is a rather vulnerable indicator of the level of development and current state of the economy of any country, the effectiveness of the implemented state policy, including employment and social protection programs, and also acts as a crucial indicator of the standard of living of the population.

Statistical analysis occupies an important place and is an integral part of the economic life of society. Determines the dynamics of development, decline, growth of social phenomena. The results of the study of mass phenomena by statistical analysis methods are an objective basis for other sciences.

The study on this issue is relevant and consists in the high need to obtain data on the situation in the labor market, as well as constant monitoring, assessment and control over them. The labour market of the Russian Federation is considered as the object of the study. The theoretical base is based on textbooks on the general theory of statistics, scientific articles on this topic, statistics of the Federal State Statistics Service, educational and methodological literature.

\section{MATERIALS AND METHODS}

Forecasting is a special scientific study aimed at identifying the prospects for the development of a phenomenon or process.

Prediction is a scientific judgment based on the construction of the probability of the state of an object in the future, alternative ways and the timing of its achievement.

One of the important directions of forecasting social development is economic forecasting - a scientific discipline, the object of which is the process of specific extended reproduction, and the object is the knowledge of the possible states of functioning economic objects in the future, the study of laws and methods of developing economic forecasts [1].

Economic forecasting is called the process of developing forecasts based on scientific methods of knowing phenomena and using the whole set of methods, tools and methods of economic prognostication [2].

The economic outlook allows us to anticipate the state of the economy in the future, as well as interest rates and other factors affecting the development of any enterprise. According to the results of the economic forecast, decisions are made related to the working personnel of the enterprise. The issues of expansion or 
reduction of production capacities, conclusion of new contracts, attraction of investments and so on are also resolved [3].

The process of creating a forecast consists in processing the currently available information about the object. As a result, they get an idea of the directions of its evolution based on an analysis of existing trends in the development of this object.

The forecast of the employed population of the Russian Federation is based on the method of exponential smoothing. Exponential smoothing is a method of smoothing time series, the computational procedure of which involves processing all previous observations. This prediction method is quite efficient and reliable. The main advantages of the method are the ability to take into account the information of the source information, the simplicity of computational operations, the flexibility of describing process dynamics [4].

The exponential smoothing method allows you to evaluate the trend parameters that characterize the trend that has developed by the time of the last observation. The basis of the method is the selection of a smoothing parameter (smoothing constant) and initial conditions.

The employment and unemployment forecast is built by exponential smoothing in STATISTICA, a statistical analysis software package developed by StatSoft, which implements the functions of analysis, search and data management, as well as the construction of various forecast models. Using the effective sign $\mathrm{Y}$ - the number of employed population, we predict the number of employed in Russia for 2020-2024, using exponential smoothing without a seasonal component. For a conclusion of the schedule it is necessary to come into the Statistics tab $\rightarrow$ Advanced Models $\rightarrow$ Time Series/Forecasting $\rightarrow$ Y (number of occupied) $\rightarrow$ Exponential Smoothing and Forecasting $\rightarrow$ Review series $\rightarrow$ Label data points with (to choose dates) $\rightarrow$ Dates from a var $\rightarrow$ Review and plot variables $\rightarrow$ Review highlighted variable $\rightarrow$ Plot. The time series graph shown in Figure 1 is displayed.

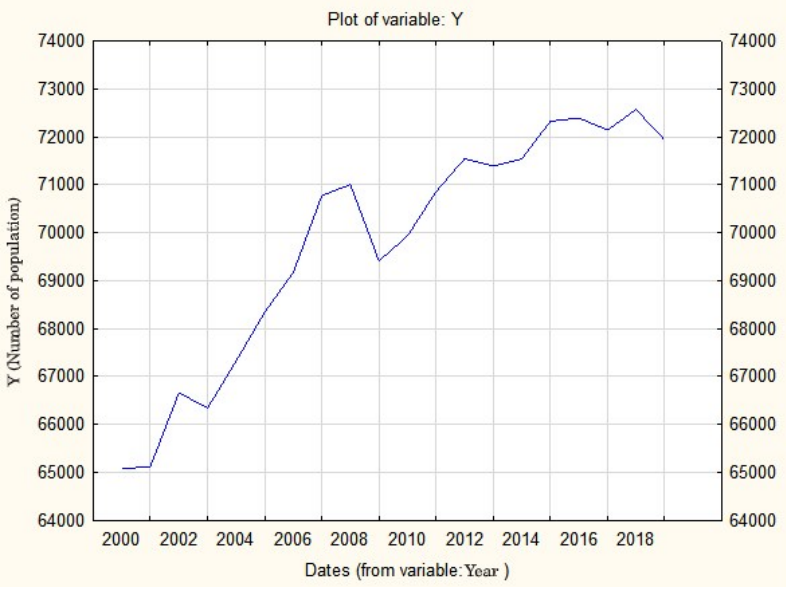

Figure 1 Time series of employed population

Next, in the Advanced $\rightarrow$ Forecast tab, we set the number 5 , which will determine the values of the population employed for five years. To select the best values for alpha and gamma, you must perform a grid search.

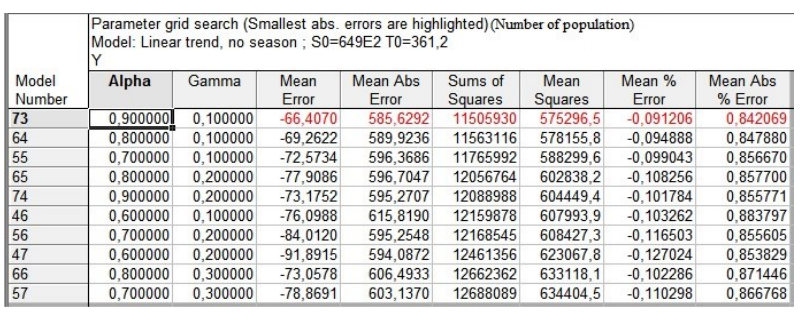

Figure 2 Grid Search for Employment Forecast

The first line shows the best alpha, gamma model values. Alpha $=0,9 ;$ Gamma $=0,1$. The average absolute error percentage was $0.84 \%$.

Then return to the Time series/Forecasting $\rightarrow$ Continue current $\rightarrow$ Advanced $\rightarrow$ Linear trend (Holt) window $\rightarrow$ set Alpha (0.9) and Gamma $(0.1) \rightarrow$ Summary: Exponential smoothing. The result is a table with three columns: the number of employees (Y), smoothed serias, and resids. That is, the original and smoothed series, as well as a number of residues. The table is shown in Figure 3. 


\begin{tabular}{|c|c|c|c|c|}
\hline \multirow[b]{2}{*}{$\begin{array}{l}\text { Year } \\
\text { (Dates) }\end{array}$} & \multicolumn{4}{|c|}{$\begin{array}{l}\text { Exp. smoothing: } \mathrm{S} 0=649 \mathrm{E} 2 \mathrm{~T} 0=361,2 \mathrm{Y} \text { (Number of population) } \\
\text { Lin.trend,no season; Alpha }=, 900 \mathrm{Gamma}=, 100 \\
\mathrm{Y}\end{array}$} \\
\hline & $\mathrm{Y}$ & $\begin{array}{c}\text { Smoothed } \\
\text { Series }\end{array}$ & Resids & \\
\hline 2000 & 65070,00 & 65250,61 & $-180,61$ & \\
\hline 2001 & 65123,00 & 65433,02 & $-310,02$ & \\
\hline 2002 & 66659,00 & 65471,06 & 1187,94 & \\
\hline 2003 & 66339,00 & 66964,18 & $-625,18$ & \\
\hline 2004 & 67319,00 & 66769,22 & 549,78 & \\
\hline 2005 & 68339,00 & 67681,21 & 657,79 & \\
\hline 2006 & 69169,00 & 68749,61 & 419,39 & \\
\hline 2007 & 70770,00 & 69641,19 & 1128,81 & \\
\hline 2008 & 71003,00 & 71272,84 & $-269,84$ & \\
\hline 2009 & 69410,00 & 71621,42 & $-2211,42$ & \\
\hline 2010 & 69934,00 & 70023,55 & $-89,55$ & \\
\hline 2011 & 70857,00 & 70327,31 & 529,69 & \\
\hline 2012 & 71545,00 & 71236,05 & 308,95 & \\
\hline 2013 & 71391,00 & 71973,93 & $-582,93$ & \\
\hline 2014 & 71539,00 & 71856,66 & $-317,66$ & \\
\hline 2015 & 72324,00 & 71949,54 & 374,46 & \\
\hline 2016 & 72393,00 & 72699,03 & $-306,03$ & \\
\hline 2017 & 72142,00 & 72808,54 & $-666,54$ & \\
\hline 2018 & 72569,00 & 72533,60 & 35,40 & \\
\hline 2019 & 71933,00 & 72893,59 & $-960,59$ & \\
\hline 2020 & & 72270,74 & & \\
\hline 2021 & & 72512,42 & & \\
\hline 2022 & & 72754,09 & & \\
\hline 2023 & & 72995,77 & & \\
\hline 2024 & & 73237,45 & & \\
\hline
\end{tabular}

Figure 3 Original, Smoothed Series and Series of Residues

A graph with three curves was also plotted, on which the blue shows the initial data; red - forecast (smoothed row); green is the residue plot (the difference between the original row and the smoothed row). The graph is shown in Figure 4.

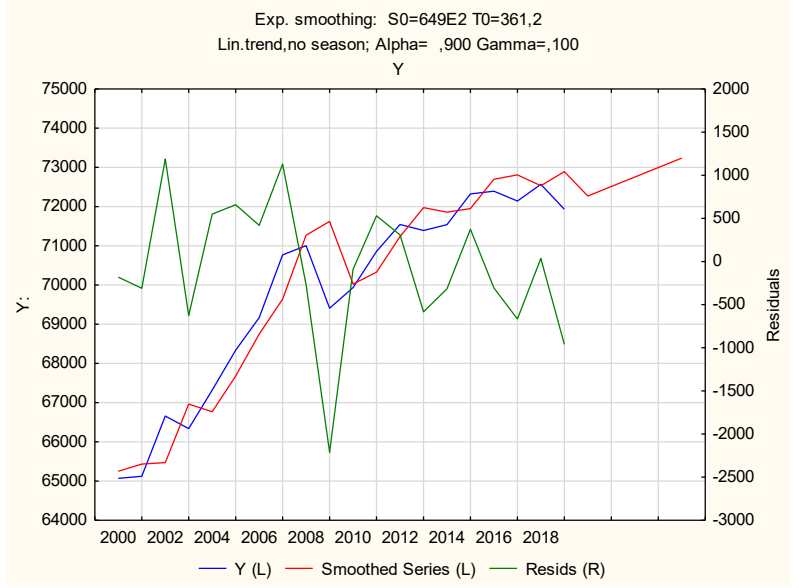

Figure 4 Original and smoothed series and series of residues

Thus, as a result of the construction of the forecast of the number of employed population for 2020-2024, there is an increase in the number of employed in the next five years.

The forecast of the number of unemployed population is also built by the method of exponential smoothing. Using the effective sign $\mathrm{Y}-$ the number of unemployed population we predict the number of unemployed in Russia for 2020-2024, using exponential smoothing without a seasonal component. For a conclusion of the schedule it is necessary to come into the Statistics tab $\rightarrow$ Advanced Models $\rightarrow$ Time Series/Forecasting $\rightarrow$ Y (number of the unemployed) $\rightarrow$ Exponential Smoothing and Forecasting $\rightarrow$ Review series $\rightarrow$ Label data points with (to choose dates) $\rightarrow$ Dates from a var $\rightarrow$ Review and plot variables $\rightarrow$ Review highlighted variable $\rightarrow$ Plot. The time series graph shown in Figure 5 is displayed.

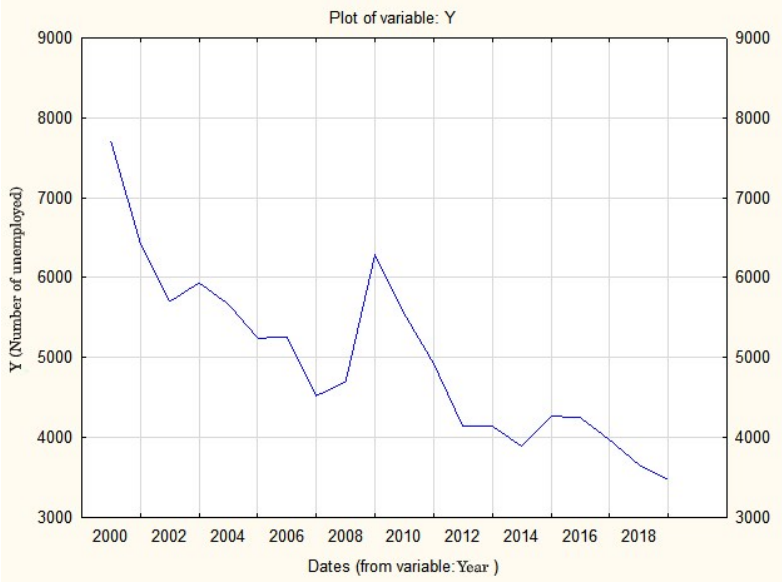

Figure 5 Time series of unemployed population

Next, in the Advanced $\rightarrow$ Forecast tab, we set the number 5 , which will determine the values of the unemployed population for five years. To select the best values for alpha and gamma, select grid search.

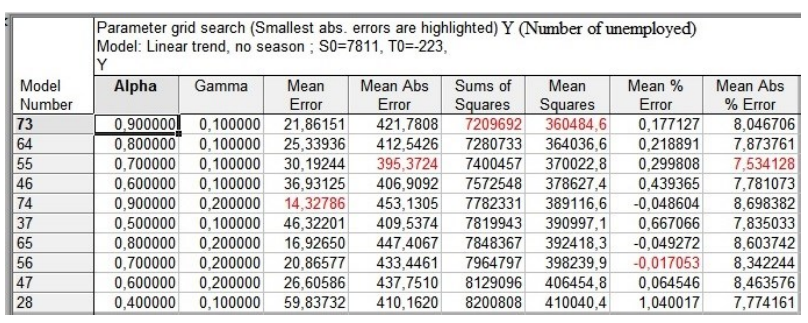

Figure 6 Grid Search for Unemployment Forecast

After analyzing the graph, we can conclude that the best model is a model with values $\alpha=0.7$ and $\gamma=0.1$. The one with the lowest average absolute error.

Next, you must return to the Time series/Forecasting $\rightarrow$ Continue current $\rightarrow$ Advanced $\rightarrow$ Linear trend (Holt) window $\rightarrow$ specify the values $\alpha=0.7$ and $\gamma=0.1 \rightarrow$ Summary: Exponential smoothing. As a result, a table with three columns was built: the number of unemployed $(\mathrm{Y})$, smoothed serias and resids. That is, the original and smoothed series, as well as a number of residues. The table is shown in Figure 7. 


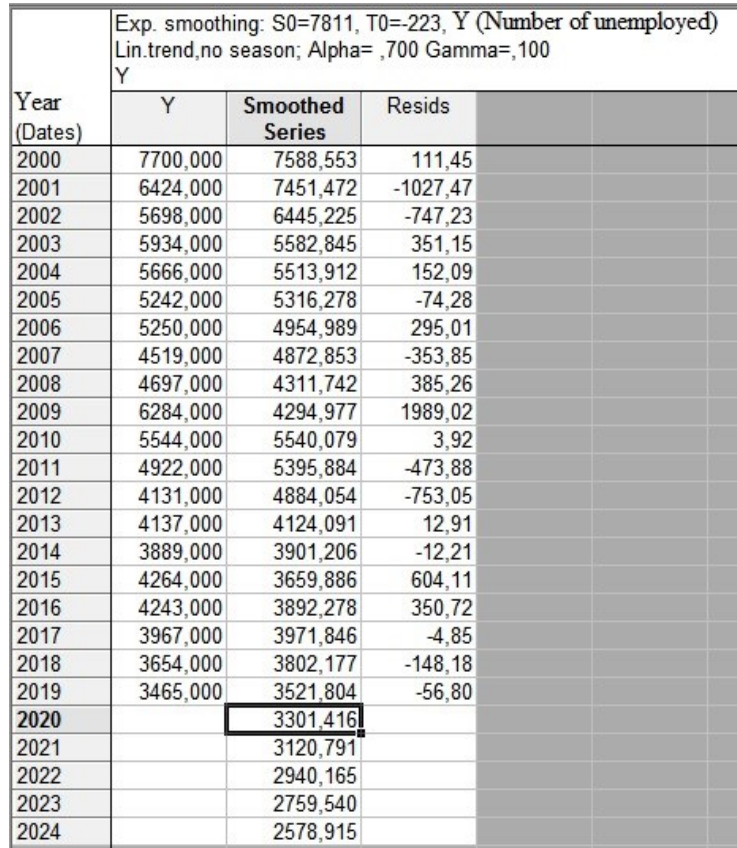

Figure 7 Original, Smoothed Series and Series of Residues

A graph was also plotted with three curves: blue shows the initial data; red - forecast (smoothed row); green is the residue plot (the difference between the original row and the smoothed row). The graph is shown in Figure 8.

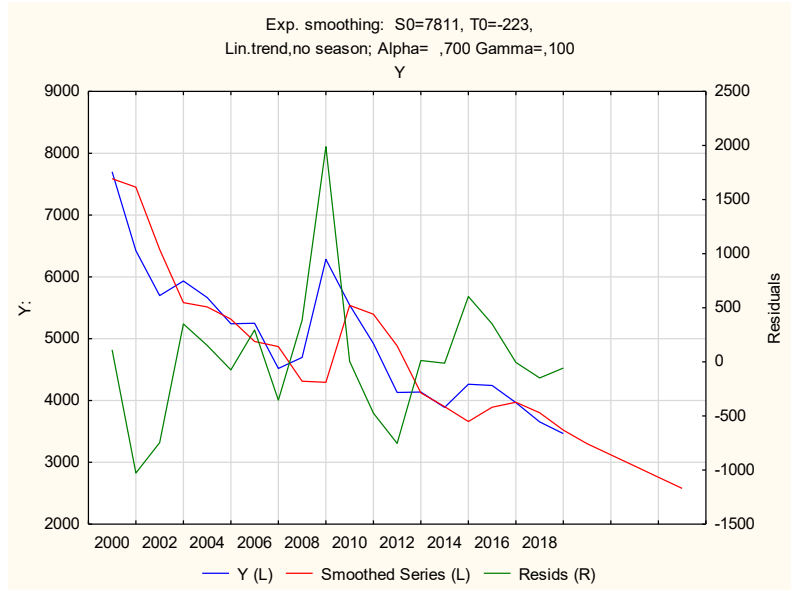

Figure 8 Original and smoothed series and series of residues

\section{RESULTS AND DISCUSSION}

Thus, as a result of the construction of the forecast of the number of unemployed population for 2020-2024, there is a decrease in the number of unemployed population in the next five years.

The exponential smoothing method allows you to build predictive models of various phenomena, as well as perform smoothing of time series, processing all previous observations. This method is widely used to predict transient time series. The result of the work is a statistical analysis and forecasting of the labor market of the Russian Federation. Forecast models of employment and unemployment rates have been constructed.

\section{CONCLUSION}

The labor market is a dynamic system that includes a set of social and labor relations according to the conditions of hiring, using and exchanging labor for wages.

The main indicators of the labor market: employment and unemployment require constant monitoring, assessment and control. The most effective tools for the study of employment and unemployment indicators are statistical analysis and forecasting methods, which allow not only to conduct a study, but also to build predictive models for the development of these indicators.

As a result, the objective was achieved: to build a forecast model of employment and unemployment using basic statistical forecasting methods.

The statistical analysis of the labour market of the Russian Federation and the construction of forecast models show that the level of employment is increasing, while the unemployment rate, on the contrary, is decreasing. This trend, of course, has a favorable effect on the development and growth of the economic system of the Russian Federation.

\section{ACKNOWLEDGEMENTS}

The work is performed according to the Russian Government Program of Competitive Growth of Kazan Federal University.

\section{REFERENCES}

[1] T. N. Babich, Forecasting and planning in the market: Textbook, M.: Infra-M, 2018, pp. 256.

[2] N. M. Gromova, N. I. Gromova, Fundamentals of economic forecasting. https://monographies.ru/ru/book/section?id=151.

[3] V. L. Vasiliev Dynamics of the main macroeconomic indicators and the causes of unemployment in Russia/V.L. Vasiliev, I.A. Galimulin, Economics and society, 4(47) (2018) pp. 170-173.

[4] L. E. Basovsky, Market forecasting and planning: Tutorial, M.: Infra-M, 2018, pp. 352.

[5] I. I. Eremina, A. G. Faizullina, Statistical analysis of the professional competence study on the example of the field «applied information science in economics», International Journal of Pharmacy and Technology, 8(3) (2016) pp. 14911 - 14925. 
[6] R. Chami, A Template for Analyzing and Projecting Labor Market Indicators. Technical notes and manuals, 2012, pp. 23.

[7] I. I. Eremina, E. V. Abrosimova, Problems of formation of competency modeling, application and information processes of enterprises and organizations in preparing IT- professionals of the economic sector at the university, MODERN JOURNAL OF LANGUAGE TEACHING METHODS, 7(12) (2017) pp. 43-48.

[8] Yu. N. Ivanova, Economic statistics: Textbook, Lomonosov Moscow State University (MSU); Converted and supplement - M.: INFRA-M, 2016, pp. 668.

[9] T. Boeri, J. V. Ours, The Economics of Imperfect Labor Markets: Second Edition, 2013, pp. 464.

[10] I. Ishmuradova, A. Karamyshev, D. Lysanov, A., Isavnin, I. Eremina, Features of software development of module tasks view of the existing software packages and their updates in the corporate information systems of the production organization, Proceedings - International Conference on Developments in eSystems Engineering, DeSE, 2019, pp. 180-183. 